\title{
IMPLEMENTASI PENDIDIKAN ANAK USIA DINI INKLUSIF DIKOTA CIMAHI JAWA BARAT
}

\author{
Chandra Asri Windarsih ${ }^{1}$, Dedah Jumiatin ${ }^{2}$, \\ Efrizal $^{3}$, Nita Sumini ${ }^{4}$, Lina Oktariani Utami ${ }^{5}$ \\ Program Studi Pendidikan PG PAUD STKIP SILIWANGI \\ chandraasriwd@yahoo.com,dedahcimahi@yahoo.com
}

\begin{abstract}
ABSTRAK
Semua anak berkebutuhan khusus perlu mendapatkan pendidikan yang layak seperti anakanak normal lainnya. Lebih luas lagi pendidikan PAUD inklusi juga dapat dimaknai sebagai reformasi pendidikan yang anti diskriminasi, serta upaya merubah sikap masyarakat terhadap anak berkebutuhan khusus. Perumusan Masalah Bagaimana implementasi program PAUD inklusif di kota Cimahi? Apa hambatan dan kendala yang dialami PAUD yang mengadakan pendidikan inklusi di kota Cimahi Sejauh mana optimalisasi program PAUD inklusif di kota Cimahi ? Tujuan Penelitian Mengetahui implementasi program yang telah dijalankan di PAUD inklusifkota Cimahi. Mempunyai solusi dan pemecahan masalah dalam PAUD inklusif yang berada dilingkungan kota Cimahi, serta tindak lanjut dari permasalahan-permasalahan yang dialami PAUD dalam mengadakan pendidikan inklusif. Pengoptimalan program PAUD inklusi yang sejalan dengan program pemerintah. Juga mempunyai kontribusi terhadap ilmu Penelitian ini menggunakan pendekatan kualitatif dengan metode deskriptif analitis. Peneliti segera melakukan analisis data dengan memperkaya informasi, mencari hubungan, membandingkan, menemukan pola atas dasar data aslinya dan tidak ditransformasikan ke dalam bentuk angka. Hasil analisis data berupa pemaparan mengenai situasi yang diteliti yang disajikan dalam bentuk naratif. Lokasi penelitian TK Penabur Cimahi Jl. Mk Wiganda Sasmita no 23 Cimahi. Sistem pembelajaran dalam sekolah inklusif mampu mengakomudasi perbedaan kebutuhan belajar setiap individu.. Dengan demikian, tujuan akhir dari semua upaya di atas yaitu kesejahteraan para penyandang cacat dalam memperoleh segala haknya sebagai warga Negara dapat direalisasikan secara cepat dan maksimal.
\end{abstract}

Kata Kunci : implementasi, PAUD, inklusif

\begin{abstract}
All children with special needs need to get a proper education like other normal children. More broadly inclusive PAUD education can also be interpreted as an anti-discrimination education reform, as well as efforts to change the attitude of society to children with special needs. Problem formulation How is the implementation of inclusive early childhood education in Cimahi city? What are the obstacles and obstacles faced by early childhood education in inclusion education in Cimahi city How far is the optimization of inclusive early childhood education program in Cimahi city? Research Objectives To know the implementation of the program that has been implemented in the inclusive PAUD Cimahi city. Have solutions and problem solving in the inclusive PAUD located within the city of Cimahi, as well as follow-up of the problems experienced by the early childhood in conducting inclusive education. Optimization of inclusive early childhood education programs in line with government programs. Also have contribution to science This research use qualitative approach with analytical descriptive method. Researchers immediately perform data analysis by enriching information, searching for relationships, comparing, finding patterns on the basis of the original data and not being transformed into figures. The results of data analysis in the form of exposure on the situation under study are presented in the form of narrative. Location of researcher kindergarten Cimahi Jl. Mk Wiganda Sasmita no 23 Cimahi. The learning system in an inclusive school is able to accommodate the different learning needs of each individual. Thus, the ultimate goal of all the above efforts is
\end{abstract}


the welfare of persons with disabilities in obtaining all their rights as citizens can be realized quickly and maximally.

Keywords: implementation, early childhood, inclusive

\section{A. PENDAHULUAN}

Setiap orang tua mengingankan anaknya terlahir dengan normal, tapi adakalanya tidak semua anak lahir dengan keadaan normal, ada anak yang dilahirkan dalam kondisi yang khusus. Anak inklusif memerlukan pendidikan yang sama sebagaimana layaknya anak-anak. Sampai saat sekalang PAUD inklusif masih menyatu dalam pembelajaran di sekolahnya baik di TK ataupun PAUD.Pengertian inklusi yaitu model pendidikan yang tidak membeda-bedakan individu berdasarkan kemampuan dan kelainan yang dimilki. Pendidikan Inklusif prinsip persamaan, keadilan dan hak individu. Secara konseptual pendidikan inklusi merupakan sistem layanan Pendidikan Luar Biasa yang mempersyaratkan agar semua $\mathrm{ABK}$ dilayanai di sekolah umum terdekat bersama teman seusianya. Dalam pendidikan inklusi menempatan $\mathrm{ABK}$ tingkat ringan, sedang dan berat secara penuh di kelas biasa. Penelitian ini dirasa sangat penting karena sampai saat sekarang masih sangat sedikit PAUD yang menyelenggarakan inklusi di Kota Cimahi Jawa Barat. Proses pembelajaran belum dilaksanakan dalam bentuk team teaching, tidak terkoordinasi dengan baik. Guru masih mengalami kesulitan dalam merumusakan kurikulum yang fleksibel sehingga dapat diterapkan ada anak normal ataupun yang PAUD inklusif, pembuatan RPM, RPH , dalam menentukan tujuan, materi, dan metode pembelajaran. Masih terjadi kesalahan praktek bahwa target kurikulum PAUD inlusifsama dengan anak lainnya serta anggapan bahwa anak cacat tidak memiliki kemampuan yang cukup untuk menguasai materi belajar. Disamping itu keterbatasan fasilitas sekolah, pelaksanaan pembelajaran belum menggunakan media, resource, dan lingkungan yang beragam sesuai kebutuhan anak PAUD inklusif. Dalam implementasi PAUD inklusif sebuah lembaga tidak bisa berjalan sendiri untuk mencapai tujuannya. Ada berbagai faktor yang mempengaruhi keberhasilan dalam mencapai tujuan tersebut. Baik itu sarana dan prasarana maupun sumber daya manusiadi dalamnya. Namun terlepas dari kedua faktor tersebut, jika dikaitkan dengan Tri PusatPendidikan maka ada 3 lingkungan yang akan mempengaruhi pendidikan pada anak yakni keluarga, sekolah dan masyarakat. Adapun tujuan PAUD inklusif yaitu :

1. Memberikan kesempatan yang seluasluasnya kepada anak yang memiliki kelaianan fisik, emosional, mental dan social atau memiliki potensi kecerdasan dan/atau bakat istimewa untuk memperoleh pendidikan yang sesuai dengan kebutuhan dan kemampuannya.

2. Mewujudkan penyelenggaraan pendidikan yang menghargai keanekaragaman tidak diskriminatif bagi semua anak sudah seharusnya anak inklusif mendapatkan haknya yaitu memperoleh pendidikan di sekolah inklusif. Terbatasnya PAUD inklusif menyebabkan anak inklusif usia dini mengalami kesulitan mengakses pendidikan yang seharusnya menjadi haknya. Jika anakinklusi dapat belajar maka anak akan merasa tenang, percaya diri, merasa dihargai, dilindungi, disayangi, bahagia dan bertanggung jawab. Inklusi terjadi pada semua lingkungan social anak, pada keluarga, kelompok teman sebaya, sekolah, dan institusiinstitusi kemasyarakatan lainnya, tanpa melupakan prinsip himanisme, uniberalisme, pluralisme, demokratis, menghormati hak azasi manusia. 


\section{B. KAJIAN TEORI DAN METODE}

Untuk memberikan pelayanan anak berkebutuhan khusus usia dini maka pendidikan anak usia dini yang telah ada seharusnya dapat menerima dan melayani anak berkebutuhan khusus. Pelayanan pendidikan anak usia dini yang memberikan pelayanan bersama-sama antara anak yang tidak mengalami hambatan dan anak berkebutuhan khusus disebut pendidikan anak usia dini inklusif.

Pendidikan inklusif adalah sistem pendidikan yang menyertakan semua anak secara bersama-sama dalam suatu iklim proses pembelajaran dengan penyelenggaraan pendidikan yang memberikan kesempatan kepada semua anak secara bersama-sama dalam suatu iklim proses pembelajaran dengan layanan pendidikan yang layak dan sesuai kebutuhan individu siswa tanpa membedakan anak dari latar belakang suku, ras, status sosial, kemampuan ekonomi, status politik, bahasa, geografis, jenis kelamin, agama/kepercayaan, dan perbedaan kondisi fisik atau mental.

Penelitian ini dimaksudkan untuk mengungkap dan mengkaji implementasi Pendidikan Anak Usia Dini yang inklusif yang berada di kota Cimahi Jawa Barat. Penelitian ini menggunakan pendekatan kualitatif yang diharapkan mampu menghasilkan uraian yang mendalam tentang ucapan, tulisan, dan atau perilaku yang dapat diamati dari suatu individu, kelompok, masyarakat, dan atau organisasi tertentu dalam suatu setting konteks tertentu yang dikaji dari sudut pandang yang utuh, komprehensif, dan holistik. dengan metode deskriptif analitis.

Adapun lokasi penelitiannya TK PENABUR CIMAHI Jl. MK Wiganda Sasmita No. 23 Cimahi. Peneliti pergi ke lokasi tersebut, memahami dan mempelajari situasi. Studi dilakukan pada waktu interaksi berlangsung di tempat kejadian. Peneliti mengamati, mencatat, bertanya, menggali sumber yang erat hubungannya dengan peristiwa yang terjadi saat itu. Hasil-hasil yang diperoleh pada saat itu segera disusun saat itu pula.

Apa yang diamati pada dasarnya tidak lepas dari konteks lingkungan di mana tingkah laku berlangsung. Peneliti segera melakukan analisis data dengan memperkaya informasi, mencari hubungan, membandingkan, menemukan pola atas dasar data aslinya dan tidak ditransformasikan ke dalam bentuk angka. Hasil analisis data berupa pemaparan mengenai situasi yang diteliti yang disajikan dalam bentuk naratif. Temuan penelitian dalam bentuk konsep, prinsip, hukum, teori dibangun dan dikembangkan dari lapangan bukan dari teori yang telah ada. Mengadakan observasi langsung, wawancara, observasi, studi pustaka, studi dokumentasi dan setelah itu akan di seminarkan untuk guru-guru PAUD inklisif.

\section{HASIL DAN PEMBAHASAN}

TK BPK Penabur untuk anak inklusi ada enam orang anak yaitu untuk kelas Kelas KB 1 Elso usia 3 tahun dan Kelas KB 2 Samuel usia 4 tahun sedangkan untuk kelas A1 Tulus, usia 5 tahun dan Kelas A3 bernama Jonathan ,usia 5 tahun dan untuk kelas besar ada dua orang juga yaitu kelas B 1 Laurencia Laras, usia 6 tahun dan kelas B2 Michael Joes, usia 7 tahun. Adapun prinsip-prinsip yang harus dilaksanakan oleh sekolahTK BPK Penabur penyelenggaran pendidikan inklusif adalah menggunakan prinsip manajemen berbasis sekolah yang meliputi Perencanaan dan evaluasi program sekolah yaitu melakukan perencanaan sesuai dengan kebutuhannya untuk meningkatkan mutu sekolah. Sekolah penyelenggara pendidikan inklusif harus mewujudkan prinsip inklusifitas sejak dari perencanaan, proses penyelenggaraan, pemantauan atau pengawasan hingga penyusunan rencana tindak lanjut penyelenggara program sekolah.

Dalam pengajaran dengan pendekatan individu menggunakan tiga langkah kegiatan utama yaitu, asesmen ( 
assesment), intervensi (intervention), dan evaluasi (evaluation). Asesmen adalah suatu penilaian yang komprehensif dan melibatkan anggota tim untuk mengetahui kelemahan dan kekuatan anak. Intervensi ada yang dikerjakan untuk membangun tingkah laku yang dikehendaki, adapula untuk meniadakan tingkah laku yang tidak dikehendaki. Membangun tingkah laku yang dikehendaki dilakukan dengan cara menceritakan tingkah laku tersebut dan menganjurkan agar siswa melakukannya. proses pembelajaran dikatakan berhasil apabila terjadi perubahan perilaku yang positip pada diri peserta didik seluruhnya atau setidaktidaknya sebagian besar.

Dalam pembelajaran yang dilakukan sudah mengikuti aturan, baik dari persiapan, kurilulum dan implementasinya sudah diterapkan walaupun masih terdapat kesulitan bagi guru untuk menyeimbangkan pembelajaran untuk PAUD inklusif, karena sangatlah mempunyai berbagai macam kendala agar anak inklusi mau diajak bekerjasama dan mengikuti pembelajaran sebagaimana layaknya anak normal. Dari pihak pemerintah Kota Cimahi masih sangat sedikit dukungannya, apalagi sarana dan prasarana yang ada sangat minim, belum adanya penunjang pembelajaran yang khusus yang diperunukan untuk anak PAUD inklusi. Semuanya masih menggunakan fasilitas disekolah yang sangat terbatas. Bahkan permaian Alat Permainan Edukatifnyapun masih dapat dikatakan sangat kekurangan. Kendala lainnya anak PAUD inklusi membutuhkan helper, setiap anak harus dibantu helper satu orang, dan helper tersebut ikut masuk diruang kelas karena helper akan sangat membantu guru jika anak inklusif tersebut tiba-tiba membutuhkan tenaganya. Ada juga kecenderungan orang tua yang memiliki anak inklusif tidak mau berterus terang keseluruhan pada sekolahnya hal ini sangat menyulitkan lembaga yang menyelenggarakan PAUD inklusi serta masih mahalnya biaya anak inklusif sehingga masih dapat dihitung oleh jari anak inklusi yang sekolah bersama-sama anak normal. Perlunya dukungan yang sangat besar baik dari pemerintah pusat ataupun pemerintah daerah demi terjadinya pendidikan inklusif yang sesuai dengan perundang-undangan di negara kita ini.

\section{KESIMPULAN DAN SARAN}

Keberadaan pendidikan anak usia dini inklusif menjadi jawaban memenuhi hak PAUD berkebutuhan khusus. Pelaksanaan pendidikan inklusif akan berhasil apabila sekolah tersebut menerapkan sesuai peraturan. Pembelajaran Pendidikan Anak Usia Dini inklusif di TK BPK Penabur telah dilakukan dengan baik sesuai peraturan pemerintah baik pusat dan Pemkot Cimahi. penyelenggaraannya humanisme, uniberalisme,pluralisme,demografi, dan menghormati hak azasi manusia.

Melaksanakan pengembangan pengelolaan PAUD menggunakan manajemen berbasis sekolah. Hambatan dan kendala yang dihadapi antara lain adalah bahwa pihak pemerintah hanya sekedar mengisyaratkan pada TK untuk menerima PAUD inklusi tanpa memberikan sarana dan prasarana yang baik. Belum ada kelas khusus untuk anak inklusi yang berbasis anak usia dini, masih bersatu dengan anak-anak normal dalam pembelajarannya sehingga kadang kala anak inklusi mendapat perlakuan yang tidak nyaman dari teman sebayanya. Sarana dan prasarana yang masih sangat terbatas untuk anak TK/ Pendidikan Anak Usia Dini inlusif, belum adanya alat permainan edukatif yang khusus untuk anak TK/ Pendidikan Anak Usia Dini inklusif. Masih terbatasnya fasilitas khusus untuk anak Optimalisasi progam berjalan belum berjalan secara optimal. Guru sudah cukup baik dalam mempersiapkan.

Adapun sarannya perlu diterbitkan surat keputusan yang berkekuatan hukum agar semua pendidikan anak usia dini bersifat inklusif. Guru/Miss sebaiknya mempunyai waktu yang seimbang antara menghadapi anak yang biasa dan anak 
yang berkebutuhan khusus/inklusif. Perlu ditingkatkan kembali kemampuan guru dalam menghadapi anak inklusif agar sesuai dan tepat sasaran, lebih sering mengikuti diklat/seminar. dari pihak Pemerintah Kota Cimahi memberikan sarana dan prasarana yang memadai dan fasilitas yang memang khusus untuk Pendidikan Anak Usia Dini inklusif.

\section{DAFTAR PUSTAKA}

Astati. 2007. Pengantar Pendidikan Luar Biasa. Jakarta: Universitas Terbuka.

Brooks, Jane. 2011. The Process of Parenting, Yogyakarta: Pustaka Pelajar, 2011.

Budi S. 2010. Sekolah Alternatif, Mengapa Tidak?, Cet. I, Yogyakarta: Diva Press.

Edi Purwanta. 2015. Modifikasi Perilaku Alternatif Penanganan Anak Berkebutuhan Khusus, Yogyakarta: Pustaka Pelajar.

Friend, Marilyn, William D. Bursuck. 2015. Menuju Pendidikan Inklusi Panduan Praktis Untuk Mengajar, Yogyakarta: Pustaka Pelajar, 2015.

http://www.kompasiana.com/simurai/shad ow-teacher-antara-riil-dan bayangan_55289155f17e617f638b459 5, diakses 30 September 2016.

Latif, Mukhtar, dkk. 2014. Orientasi Pendidikan Anak Usia Dini Teori dan Aplikasi, Jakarta Kencana.

Law Nolte, Dorothy dan Rachel Harris. 2016. Anak-Anak Belajar dari Kehidupannya Nilai-Nilai Parenting Klasik Dunia, Penerjemah :Helly Prajitno Soetjipto, Yogyakarta : Pustaka Pelajar.

Nur Abdul Hafizh Suwaid, Muhammad. 2010. Prophetic Parenting Cara Nabi Mendidik Anak, Penerjemah: Farid Abdul Aziz Qurusy, Yogyakarta: ProU Media, dalam PAUD Inklusi, Semarang: $\quad$ PPPAUD-DIKMAS JATENG, 2016. PPPAUD-DIKMAS JATENG, Strategi Pelibatan Orang tua dan Masyarakat
Sastry, Anjali \& Blaise Aguairre. 2014. Parenting Anak dengan Autisme (Solusi, Strategi dan Saran Praktis untuk Membantu Keluarga Anda), Yogyakarta: Pustaka Pelajar. 